visitor or family doctor, or taken directly by parents once they become aware of the service. The orthoptist then decides either that there is no problem or that the child must be referred to the ophthalmologist.

With co-operation from orthoptists visual screening of all children would become possible in line with the Court report programme for basic surveillance. ${ }^{2}$ The success of such a scheme would depend on several features. Firstly, a review of visual development at 8 months of age by the child health visitor, who would have received extra training in orthoptic techniques. Secondly, testing for visual defects of one or both eyes and for a squint would be performed at $2 \frac{1}{2}$ to 3 years of age by orthoptists, with an atropine refraction at this stage. Thirdly, these tests would be repeated at 4 to $4 \frac{1}{2}$ years of age by orthoptists. Finally, the annual school vision examinations by nurses or health visitors would also be continued. Naturally any child, however young, who is suspected of having visual difficulties would be entitled to appropriate vision testing and treatment as at present. A positive family history of squint or "lazy" eye is still an important indicator for early check ing of children.

If such a scheme were introduced, then the early detection of visual problems would allow the major part of the treatment to be carried out before the child starts school at 5 . The challenge of providing an integrated child health service, at least with regard to vision, can be met. The workers and the methods are available. We must try to ensure that there is a proper administrative structure for these plans to come to fruition.

\footnotetext{
${ }^{1}$ Ingram, R M, British fournal of Ophthalmology, 1977, 61, 4.

2 Committee on Child Health Services (chairman, Professor S D M Court), Fit for the Future. London, HMSO, 1976.
}

\section{Helping mothers to love their babies}

Only 15 years ago a student could qualify as a doctor without having given much thought to the idea that parents might harm their own children. Today all who work with children, and most of those who do not, are fully familiar with the concept of "battered babies" or "non-accidental injury." Dealing with such injuries is now part of the routine of a paediatrician's life and an informed guess at the incidence of chronic neurological handicap in children from this cause in the United Kingdom has produced a figure of about 400 new cases each year. ${ }^{1}$ Although some non-accidental injuries may have been missed in the past, it seems unlikely that increased awareness of the problem wholly accounts for the rapid increase in apparent incidence. What has gone wrong? Why do parents harm their own children ? Can we suggest any possible ways of promoting better parental caring behaviour?

Klaus and Kennell have recently summarised what we know of the factors which may be important in forming bonds between infants and parents, and their review has important implications for anyone working with newborn babies and their mothers. ${ }^{2}$ Most studies on this subject have concerned mother and baby, but we must not forget the importance of father to baby attachment.

Babies who have been separated from their mothers after birth because of prematurity or illness are more often the subjects of later physical abuse or failure to thrive without organic cause than those who have not been separated. Observations in animals have shown that rejection of the young by the mother is common when mother and baby are separated soon after birth. In the goat, for instance, the first 10 minutes after birth is critical to the mother's acceptance of the kid. In primates the critical period appears to be longerone or two days.

Studies with human mothers and babies have also shown that intimate contact in the early days after birth is supremely important in determining the future relationship between mother and child. In Cleveland, Ohio, two groups of mothers were studied. The first group had brief contact with their babies soon after birth and again at about six hours and then bottle fed them every four hours with no contact between feed times. The second group were given their babies for an hour soon after birth and had five hours of extra contact on each of the first three days. The mothers and babies were observed at one month, ${ }^{3}$ one year, ${ }^{4}$ and two years ${ }^{5}$ and on each occasion the mothers in the second group showed evidence of closer attachment to their babies. At one month they spent more time during feeds fondling their babies and looking at them face to face, and were less inclined to go out leaving the baby with someone else. They appeared to take more interest when the baby was being examined by the doctor. Similar differences persisted at one year, and at two years there was a significant difference in speech patterns between the two groups of mothers when talking to their children. The mothers who had had extended contact with their newborn babies used more varied and complex speech patterns, asked more questions of their children, and issued fewer commands.

The same workers have also studied the behaviour of mothers on first contact with their babies, looking for evidence of species-specific behavioural patterns which it may be necessary to encourage to promote normal mother to baby attachment. ${ }^{6}$ Mothers in hospital presented with their naked babies soon after birth will usually begin by touching the baby's limbs with their fingers and later progress to holding the trunk with their palms. This sequence of events is delayed if the baby is clothed. In addition to this touching and holding of the baby, direct eye to eye contact appears to be important.

The newborn infant can fix his eyes on a face very soon after birth, and many mothers find this response extremely rewarding and important in enabling them to relate to the baby as a person. Observations at home deliveries have shown maternal behaviour to be different from that in hospital. At home, the mother is much more in charge: immediately after delivery she often seems to be elated, and some mothers have described sensations similar to orgasm then. She is more likely to hold her baby in her arms and to explore his face with her fingertips. She may put the baby to the breast soon after birth, when he will lick and mouth at the nipple-imbibing mother love, not milk.

Clearly we need to review our present practices in many newborn nurseries. In some, pressures of work and the limitations of present accommodation make it difficult to adhere to an ideal policy. Nevertheless, the fall in birth rate should give midwives more time to devote to these matters. Thus the baby should be shown briefly to the mother immediately after birth. She should then be allowed to rest while the placenta is delivered and any necessary stitching done. After that, if they wish, both parents should be allowed to be alone with their baby in private for between 30 and 45 minutes (the father having witnessed the birth). During this time, the mother should be allowed to hold her naked baby to her under a heat shield and may put the baby to the breast if she wishes. 
(Mothers who put the baby to the breast early are more likely to succeed in prolonged breast-feeding.) On the postnatal wards the mothers should have their babies with them for as long as they wish and should have ready access to them at all times. For immature and sick babies this sequence of events will have to be amended, but both parents should be allowed as much access to the baby as possible. Provided he is kept warm, there is no reason why an otherwise healthy premature baby must be rushed away to the special care unit immediately after birth. Time spent with the mother at this time may be of enormous benefit.

Over the last two decades major advances have been made in the care of sick newborn babies and there are still good reasons for advising hospital delivery. Nevertheless, mother and baby should be allowed to grow together as a unit and doctors should do all they can to preserve the functional integrity of that unit. There can be few more poignant tragedies than that of the baby whose life and future potential are saved by excellent technical neonatal care but whose potential is never realised because our failure to promote parental attachment has resulted in neglect or abuse.

${ }^{1}$ MacKeith, R, Developmental Medicine and Child Neurology, 1974, 16, 216.

${ }^{2}$ Klaus, M H, and Kennell, J H, in Recent Advances in Paediatrics, No 5, ed D Hull. Edinburgh, Churchill Livingstone, 1976.

${ }^{3}$ Klaus, M H, et al, New England fournal of Medicine, 1972, 286, 460.

4 Kennell, J H, et al, Developmental Medicine and Child Neurology, 1974, 16, 172.

${ }^{5}$ Ringler, N M, et al, fournal of Pediatrics, 1975, 86, 141.

${ }^{6}$ Klaus, M H, et al, Pediatrics, 1970, 46, 187.

\section{Health Service Commissioner}

Any complaints system, whether in the National Health Service or in any other complex organisation, ought to fulfil a double purpose. Firstly, it should redress the grievances of individuals when these are justified. Secondly, however, it should draw attention to those more general problems of which the complaints may simply be the symptom. In the case of the NHS the Health Service Commissioner investigates individual cases, but it is the responsibility of the allparty Select Committee on the Parliamentary Commissioner to follow up his reports and explore their wider implications. The task of the Parliamentary Committee is at least as important as that of the Commissioner himself, and we regret, therefore, that its latest inquiry ${ }^{1}$ has concentrated on raking over the details of cases already investigated as distinct from calling attention to underlying policy issues.

For example, the MPs spent considerable time crossexamining a consultant who withdrew from treating a patient after the lodging of a complaint. In the end they concluded, very fairly, that his decision "arose from an accumulation of administrative and similar pressures," rather than being a protest against the Health Service Commissioner's intervenion. Had it been the latter, then of course the case might have raised some serious issues; but why was the Parliamentary hammer used to deal with such a very specific, indeed idiosyncratic, case? Perhaps the only bonus to emerge from the lengthy interrogation was that it might have taught MPs something about the enormous pressures under which consultants work. In particular, they might well draw the attention of their Parliamentary colleagues to the additional problems created for doctors when MPs press for the early treatment or admission of their constituents: perhaps someone should draw up a Parliamentary code of professional etiquette to enforce some self-restraint.

But does the education of MPs require such elaborate, time-consuming procedures? More important still, does the performance of the Health Service Commissioner's task require that every complaint, whatever its nature, should be investigated with the same intensity-thus adding to the pressures on those working in the NHS ? The point was briefly raised by one member of the Select Committee, Mr Dan Jones, when he queried the investigation of a complaint about a $£_{1} \cdot 15$ charge for the replacement of a spectacle lens. "I must confess that it nauseates me to see such an administrative pirouette for such a piffling sum of money," said Mr Jones. Unfortunately the committee did not follow up his remarks; yet these underline a dilemma which will have to be faced, sooner or later. On the one hand, it is right that all complainants should be given an opportunity to have their grievances redressed; and, furthermore, even a seemingly trivial case may on occasion raise a major issue of principle. On the other hand, it is absurd that so much highly paid time should be devoted to the fullscale investigation of the small change of patient discontent. Perhaps an improved local system for dealing with complaints will help; if not, possibly the Health Service Commissioner will have to be more discriminating.

The Select Committee also missed the chance of taking up yet another important general issue underlined by two of the specific cases which it examined: the grievances generated by the long waiting lists for hip-replacement surgery. Here is a classic example of a technical innovation creating new opportunities for treatment and arousing patient expectations which, at present, cannot be satisfied. In the outcome it is the doctors and others in the front line who are the targets of patients' complaints about the queues; yet it is the policy makers at the Department of Health and Social Security who largely determine resource allocation and therefore should carry the responsibility for frustrated hopes. Given the evidence of public discontent disclosed by the complaints addressed to the Health Service Commissioner, the Select Committee could therefore usefully cross-examine the DHSS on how far its resource allocation priorities will permit the demands from patients to be satisfied.

${ }^{1}$ First Report from the Select Committee on the Parliamentary Commissioner for Administration Session 1976-77. HC282, London, HMSO, 1977. 